\title{
Use of time-depth recorders to determine fishing depth of commercial setnets and inform management in Cook Inlet, Alaska
}

\author{
David W. Welch", Aswea D. Porter and Paul Winchell
}

\begin{abstract}
Background: Access to harvestable surpluses of sockeye salmon is often limited by incidental harvest of Chinook salmon in the mixed-species gillnet fishery of Cook Inlet, Alaska, particularly in years of low Chinook abundance. This is restricting economic opportunity and creating allocation conflict between user groups. Prior work quantified differences in migration depth of Chinook and sockeye salmon and suggested that the use of shallower surface-hung fixed gillnets ("setnets") could potentially reduce Chinook interception rates while leaving sockeye harvest rates relatively stable. However, lack of knowledge concerning the actual fishing depth of setnets was identified as an important uncertainty in implementing regulatory change. Cook Inlet is subject to strong tidal currents and high suspended sediment loads which make the water virtually opaque, preventing simple visual assessment of the depth of fishing nets.
\end{abstract}

Results: We used time-depth recorders attached to setnets within Cook Inlet to record the leadline depths of 29, 36, and 45 mesh setnets during all fishing openings in 2015. Recorded depths were far shallower than the physical construction of the nets would suggest for most of the tidal cycle (as shallow as $0.6 \mathrm{~m}$ ), and only near slack water did they extend down to near their maximum potential depth.

Conclusions: In this study, we demonstrate how time-depth recorders can be used to document the behavior of fishing gear and provide information useful for fine-tuning changes to regulations governing fishing net construction. Most Chinook harvest presumably occurs around slack water because it was only during these narrow time windows that the nets extended into the depths where Chinook primarily migrate. Switching to reduced-depth nets would avoid much of the Chinook distribution. In contrast, sockeye are potentially exposed to nets over much of the tidal cycle, although data on the efficiency of nets at various stages of the tide are lacking. Reduced sockeye harvest rates might be compensated for by some increase in allowable fishing time.

Keywords: Gill nets, Setnets, Time-depth recorder, Chinook, Sockeye, Pacific salmon, Depth of migration, Fisheries management

\section{Background}

Chinook salmon (Oncorhynchus tshawytscha) stocks across Alaska have experienced severe declines in abundance in recent years. These declines are likely the result

*Correspondence: david.welch@kintama.com

Kintama Research Services, Ltd., 4737 Vista View Cr., Nanaimo, BC V9V 1N8, Canada \\ Ciomed Central}

of reduced marine survival that has occurred in parallel with statewide reductions in Chinook growth at sea and falling mean age at maturity $[1,2]$, suggesting a potential causal relationship. However, irrespective of the underlying cause of the decreases in Chinook abundance, the abundance of returning sockeye salmon (O. nerka) has remained at high levels, complicating management 
because the return timing of these two species overlaps while the priorities of different user groups may not.

Within Cook Inlet, two major commercial fisheries operate: a nearshore setnet fishery based on anchored surface gillnets and operating within 1 or 1.5 nautical miles $(1.9$ or $2.8 \mathrm{~km}$ ) of the beach (situated mainly along the eastern shore of Cook Inlet) and a driftnet fishery using surface gillnets operating in central Cook Inlet offshore of the setnet boundary. Sport fishing is also very popular in the Kenai River and supports a commercial guiding industry. The driftnet and setnet fisheries focus on sockeye because of the abundance of this species, but the eastside setnet fishery (ESSN) also catches Kenai River Chinook, which are the priority target of the sport fishery. As a result, in recent years both the ESSN sockeye fishery and the Kenai River sport fishing industries have been severely limited because even small harvests of Chinook would reduce escapement below minimum permissible limits. In contrast, the driftnet fishery rarely catches Kenai River Chinook and substantial fishing effort has therefore been re-allocated to this fishery as managers try to avoid overescapement of Kenai River sockeye to the spawning grounds. However, the driftnet fishery also increases harvest of multiple species of salmon (sockeye, coho, and chum) bound for more northern regions of Cook Inlet, which have their own conservation and allocation concerns.

Harrison and Loring [3] provide an excellent description of the various gear types in Cook Inlet and the intense conflict between user groups over allocation which has been exacerbated by the downturn in Chinook abundance. A useful historical summary of the development of the Cook Inlet salmon fisheries is available [4], as well as a number of recent sociological studies examining the conflict [5-9]. A number of opinion pieces and newspaper articles also outline the recent history of developments in this highly charged fishery [5, 10-14]. As a result of this complex web of co-migrating salmon species, gear types, disparate fishing locations, and range of established and newer user groups, managers must make decisions regarding implementation of fishing restrictions and allocations within a politically and socio-culturally complex environment [15].

An earlier acoustic fish tagging study in Cook Inlet demonstrated that sockeye primarily migrated in the near-surface zone just offshore of the ESSN boundary, with their median depth of migration approximately $3 \mathrm{~m}$ shallower than Chinook [16]. If this earlier study applies within the ESSN area, then this difference in the vertical distribution of the two species potentially provides the opportunity for ESSN fishers to use shallower nets to better focus setnet fishing effort on sockeye while reducing the harvest of Kenai River Chinook. Lost sockeye harvest from a reduction in net depth could presumably be compensated for by increasing allowable net lengths or the number of fishing days [16]. However, these management alternatives are partly dependent on how the bottom depth of ESSN setnets varies over the tidal cycle which was unknown (see [17] for details and [18] for a response).

The maximum (bottom) depths of ESSN setnets are unknown because of the strong tidal currents and the near-complete opacity of the water due to a combination of glacial rock flour from runoff and fine suspended mud (net visibility from the surface was often $<1 \mathrm{~m}$ ). To reduce uncertainty concerning how shallow nets might fish relative to the current "standard" net (45 meshes deep of maximum $6^{\prime \prime}$ stretched measure $(15.2 \mathrm{~cm})$ gillnet [19]), we developed a cooperative agreement with four ESSN fishermen to directly measure the bottom depth of their nets in 2015 using time-depth recorders (TDR). These data allowed an assessment of the maximum depth of the standard 45 mesh net and shallower (29 and 36 mesh deep) nets over the tidal cycle. Using the typical mesh sizes actually used in the fishery $\left(5^{\prime \prime}\right.$, or $\left.12.7 \mathrm{~cm}\right)$, 29,36 , and 45 mesh deep nets have maximum potential fishing depths of ca. 3.7, 4.6, and $5.7 \mathrm{~m}$.

\section{Methods}

In the ESSN fishery, nets are deployed perpendicular to shore within the 1 or $1.5 \mathrm{~nm}$ ESSN fishing zone (1.9 or $2.8 \mathrm{~km})$. They are secured on the offshore end to a large anchor and on the shore end to a post driven into the beach. At periodic intervals of $\sim 60 \mathrm{~m}$, the leadline and floatline are each secured to lines connecting back to a single horizontal line (forming a rotated letter "Y" when viewed from the side). The bitter end of the single line is then tied to a surface floatline leading down to a sandbag anchor. This arrangement holds the leadline roughly below the floatline.

Initially, we planned to instrument the leadline of equal numbers of shallow (29 mesh) and conventional deep (45 mesh) nets with time-depth recorders [20]. However, some changes occurred after the TDRs were distributed, resulting in fewer conventional nets being instrumented than originally planned. As a result, depth recorders were attached to the midpoint of the leadlines of 7 shallow and 3 conventional depth nets. In addition, we instrumented one shallow and one deep net on the breastline with depth recorders at $1 / 4,1 / 2$, and $3 / 4$ of the total depth of the net, as well as an additional TDR at the midpoint of the immediately adjacent leadline (The breastline is a vertical rope hung between the surface (float) and bottom (lead) lines, to which the gillnet mesh is secured to form $64 \mathrm{~m}\left(210^{\prime}\right)$ long panels.) Nets were fished at two locations within the ESSN separated by $\sim 40 \mathrm{~km}$ (Fig. 1). One 


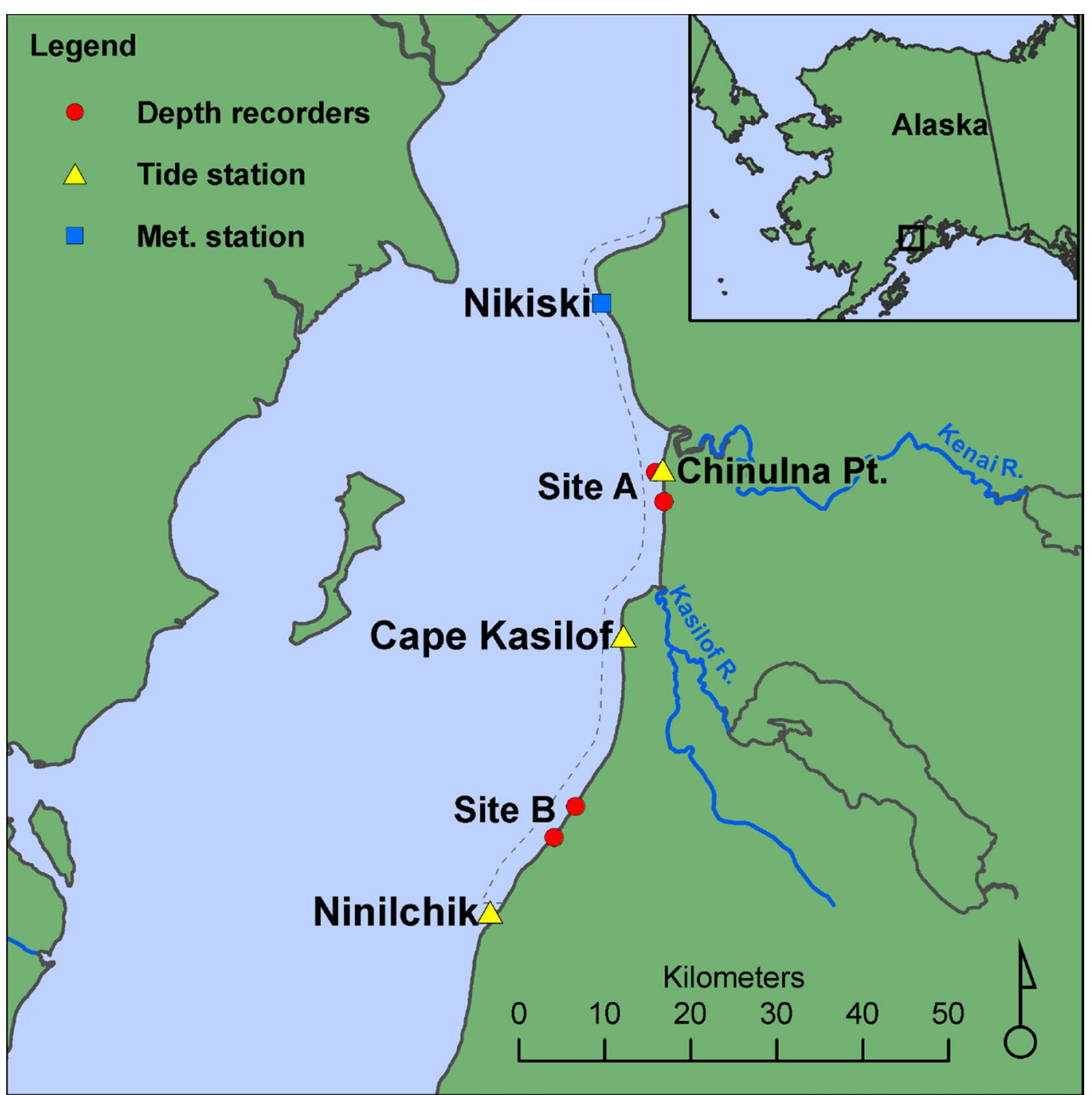

Fig. 1 Map of net depth study area in Cook Inlet in 2015. Red circles are fishing locations where depth recorders were deployed on nets; the dashed line demarks the ESSN boundary. Yellow triangles are sites of NOAA tide predictions, and the blue square is where atmospheric pressure was recorded (atmospheric pressure data were used to calculate water depths; see "Methods"section)

fisherman also deployed a recorder on the leadline of a 36 mesh net. Table 1 provides more detail on the individual nets fished.

Nets were instrumented with Sensus Ultra TDRs manufactured by ReefNet Inc., (Mississauga, Ontario, Canada; dimensions were $25 \times 33 \times 44 \mathrm{~mm}$ ). TDRs were secured to the nets using electrical tape spirally wound around the body of the TDR and the rope with a perforated straw sandwiched between them and protruding beyond the tape to allow rapid pressure equalization. TDRs remained fixed on the nets for the duration of the 2015 fishing season and recorded net depth every $10 \mathrm{~s}$ to a stated resolution of $12 \mathrm{~mm}$ and an accuracy of $\pm 30 \mathrm{~cm}$. (In our own testing of the specific TDRs used in this study, we found that accuracy was substantially better than this; see below). The recorders also simultaneously recorded temperature to a resolution of $0.01{ }^{\circ} \mathrm{C}$ and an accuracy of $0.8^{\circ} \mathrm{C}$. At the end of the study, the fishermen removed the TDRs and returned them for download and analysis.

After return, we screened the raw data from the TDRs to remove measurements recorded while the nets were briefly lifted to the surface to remove fish, as well as measurements before and after the nets were deployed. To identify these periods, we plotted the time series in $1 / 2 \mathrm{~h}$ intervals and recorded the times to the nearest $5 \mathrm{~min}$ before and after each sudden change in pressure where the sensor closely approached atmospheric pressure. 
Table 1 Summary of TDR deployment on Cook Inlet setnets, 2015

\begin{tabular}{|c|c|c|c|c|c|c|c|c|c|}
\hline \multirow[t]{2}{*}{ Site } & \multirow[t]{2}{*}{ Mesh } & \multirow[t]{2}{*}{ Net } & \multirow[t]{2}{*}{ TDR } & \multicolumn{3}{|c|}{ Net construction } & \multicolumn{3}{|c|}{ Days fished } \\
\hline & & & & Mesh size (in.) & Material & Length (ft.) & $N$ & First & Last \\
\hline \multirow[t]{7}{*}{ Site A } & 29 & $1^{\mathrm{a}}$ & 13,904 & 5 & Monofilament & 210 & 11 & 09-Jul & 30-Jul \\
\hline & & 2 & 13,908 & 5.125 & Monofilament & 210 & 11 & 09-Jul & 30-Jul \\
\hline & & 3 & 13,893 & UN & UN & UN & 4 & 09-Jul & 26-Jul \\
\hline & & 4 & 13,895 & UN & UN & UN & 11 & 09-Jul & 01-Aug \\
\hline & 45 & $1^{\mathrm{a}}$ & 13,889 & 5 & Multistrand & 210 & 11 & 09-Jul & 30-Jul \\
\hline & & 2 & 13,890 & 5.25 & Multistrand & 210 & 11 & 09-Jul & 30-Jul \\
\hline & & 3 & 13,891 & 5.25 & Multistrand & 210 & 11 & 09-Jul & 30-Jul \\
\hline \multirow[t]{4}{*}{ Site B } & 29 & 1 & 13,842 & 5 & Monofilament & 210 & 11 & 02-Jul & 20-Jul \\
\hline & & 2 & 13,847 & 5 & Monofilament & 210 & 6 & 06-Jul & 18-Jul \\
\hline & & 3 & 13,866 & 5 & Multistrand & 150 & 20 & 04-Jul & 10-Aug \\
\hline & 36 & 1 & 13,874 & 5 & Multistrand & 150 & 19 & 02-Jul & 06-Aug \\
\hline
\end{tabular}

Sites $A$ and $B$ are mapped in Fig. 1. Mesh refers to the number of $\sim 5^{\prime \prime}(\sim 13 \mathrm{~cm})$ square meshes that determine the depth of the net. TDR: serial number of the timedepth recorder (used to select the net to view on the animator)

in. inches, $f t$. feet, UN unknown, $N$ number $(1$ inch $=2.54 \mathrm{~cm} ; 210$ feet $\approx 64 \mathrm{~m})$

a These nets were equipped with additional depth recorders on the breastline at $1 / 4,1 / 2$, and $3 / 4$ of the depth of the net, as well as on the center of the leadline

Next, we calibrated the TDRs to improve the accuracy and precision of the pressure measurements. For each day of deployment, we extracted a 15 min subset of the data in the interval shortly after the nets were recovered when the TDRs were on the surface (reporting atmospheric pressure). We then averaged the difference between the pressure readings from each sensor and the atmospheric pressure recorded each hour at the meteorological station at Nikiski, Alaska, which is situated 20 and $60 \mathrm{~km}$ from Site A and B, respectively (NOAA station number 9455760). We applied this sensor-specific correction factor to all pressure readings. Calibration increased the depths by an average of $5.9 \mathrm{~cm}$ (range $2.39-11.07 \mathrm{~cm}$ ).

To calculate depth from pressure, we used the following equations: $P_{\text {total }}=P_{\text {atmosphere }}+P_{\text {water }}$, and $P_{\text {water }}=\rho g h$ where $P_{\text {atmosphere }}=$ atmospheric pressure (Pa), $\rho=$ density of ocean water (assumed $\left.1025 \mathrm{~kg} / \mathrm{m}^{3}\right), g=$ gravitational acceleration $\left(9.807 \mathrm{~m} / \mathrm{s}^{2}\right)$, and $h=$ depth $(\mathrm{m})$. Measurements of atmospheric pressure at hourly intervals were obtained from the meteorological station at Nikiski, Alaska. Over the course of the study, there were $10 \mathrm{~h}$ when no atmospheric pressure was recorded (of 984 measurements taken between July 1st and August 10th), and we populated these with the midpoint between the values on either side. The maximum difference in pressure between readings on either side of missing values was $0.9 \mathrm{mb}$. We then linked the pressure measurements on the sensors to the atmospheric pressure closest in time.

We then filtered the depth estimates to remove variability due to electrical noise and/or wave action with a second-order low-pass Butterworth filter implemented with the signal package [21] in program $\mathrm{R}$ [22]. This filter removes the high-frequency variation in the data and retains the lower frequency patterns due to variation in tidal currents that can influence net depths. As a simple measure of the variability removed by filtration, we calculated the ratio of the standard deviation (SD) of the filtered to the unfiltered data. When the data were grouped by net type, deployment location, and tidal period (see below for definition), the SD ratios ranged between 0.962 and 1.0 with a median of 0.997 , indicating that the filter removed little variability.

Because net depths are likely influenced by ocean currents, we analyzed the depth data relative to current strength across all days of net deployment. We used the times of high and low tides to reference current strength. Since these occur at different times on different days, we divided the $24.83 \mathrm{~h}$ tidal cycle into 24 nearly equal time periods ("tidal hours") and then allocated the depth measurements into the appropriate tidal hour based on the time it was recorded. At each site, the times of high tides were approximately centered within the 6th and 18th bins, and times of low tides in the 12th and 24th bins. Because the times between high and low tides vary slightly, the size of these tidal hours ranged between 53 and 77 min for Site A and 56-74 min for Site B (average of $62 \mathrm{~min}$ for both sites).

The first step in creating the tidal hours was to define the start and end times of each interval between successive high and low tides. The start of each interval was $\operatorname{Ttide}_{(i)}+\left(\operatorname{Ttide}_{(i+1)}-\operatorname{Ttide}_{(i)}\right) / 12$, and the end of the interval was $\operatorname{Ttide}_{(i+1)}-\left(\operatorname{Ttide}_{(i+1)}-\operatorname{Ttide}_{(i)}\right) / 12$, where 
Ttide is the specific time of high or low tide and 12 is the number of bins (in this case 6) multiplied by 2 in order to obtain $1 / 2$ a bin size. We then divided these intervals into 5 periods of equal length which resulted in 6 bins when combined with the start and end times of each interval $\left(\mathrm{start}_{i}-\mathrm{t} 1_{i}, \mathrm{t} 1_{i}-\mathrm{t} 2_{i}, \mathrm{t} 2_{i}-\mathrm{t} 3_{i}, \mathrm{t} 3_{i}-\mathrm{t} 4_{i}, \mathrm{t} 4_{i}-\mathrm{t} 5_{i}\right.$, end $_{i}-$ start $\left._{i+1}\right)$ for a total of 24 bins in the tidal day. Finally, we divided the depth data into the appropriate tidal hours for each deployment site.

We obtained predictions of the times of high and low tides from stations at Chinulna Point, Cape Kasilof, and Ninilchik (Fig. 1; NOAA harmonic stations 9455735, 9455711, and 9455653). We applied the tidal predictions from the Chinulna Point station to the pressure data from Site A because these were at essentially the same location $(<3.5 \mathrm{~km}$ distant). Because Site B was located between the tidal stations at Cape Kasilof $(21.8 \mathrm{~km})$ and Ninilchik $(13.8 \mathrm{~km})$, we interpolated the times of high and low tides for this site by assuming a linear change with distance. Times of predicted high and low tides differed by an average of 26.7 and $39.7 \mathrm{~min}$, respectively, between Cape Kasilof and Ninilchik. We used the midpoint of the two nets fished at Site B (separated by $4.5 \mathrm{~km}$ ) as the location for this site.

A number of assumptions were required in creating the net animation tool. First, we assumed that the individual meshes forming the gillnet were $12.5 \mathrm{~cm}$ in height (a typical mesh size used in the fishery) and that this height remained constant through time. Second, we assumed that the net was moving in response to the tidal current as a series of linked piecewise-linear segments, with the depth of the end points defined by the depth recorder data. In the absence of independently measured current data, we used the net depth itself to infer the relative strength of the current (the direction and strength being indicated by a faded arrow on the animations). We indicate current strength by making the arrow length proportional to the angle from vertical between the floatline and the bottom of the net, if the bottom of the net was free to move horizontally outward. We also assumed that the direction the center of the net moves is determined from the tidal direction and changes when the net reaches a local maximum in recorded depth. The display is facing west, so the net billows to the right (north) when the tide is rising and to the left (south) when it is falling. Finally, since both the breastline and leadline are typically anchored to the seabed, we illustrated the net in cross section as a "C-" or "bag-" shape by constraining the net segments after the middle to angle back toward the floats, so that the leadline remains positioned below the floatline. This final assumption can be relaxed in the animation by clicking on one of the selection buttons, and the net can be animated with a free-floating leadline, which would be more appropriate if the leadline was not periodically tethered to the seabed (the former is standard practice in the ESSN fishery).

\section{Results}

The complete time series of depth data for each net is available in Additional files 1, 2, 3 and 4.

\section{Animations}

The JavaScript animator of the net depth data is available from http://kintama.com/animator/net/. The animations can be customized using the eight buttons along the top left to alter the display and the slider to the right to change the speed (Fig. 2). The button with a three dot icon on the top left provides a drop down list of the different nets and the button on the far right of the group of eight displays the Chinook and sockeye depth distributions reported in Welch et al. [16]. The animations should also be visible with recent versions of most web browsers.

\section{Summary of net depths}

There was a large swing in recorded leadline depth as ocean currents changed with the stage of the tide (Fig. 3, top panel). All nets were held in shallow water for much of the tidal day and only approached their maximum potential depths during the 4-6 h when tidal currents were close to slack. Median net depths measured at the leadline across tidal hours ranged between 1.4 and $3.2 \mathrm{~m}$ for the 29 mesh nets, $1.6-4.1 \mathrm{~m}$ for the 36 mesh net, and $1.6-5.2 \mathrm{~m}$ for the 45 mesh nets. Median leadline depths during those parts of the tidal cycle when the tidal currents were strong were remarkably similar across all three net types.

We can estimate the proportion of time the nets extended to a given depth by rearranging the tidal hours so that they are sorted by depth rather than chronologically (Fig. 3 bottom panel; Table 2). For the 6 tidal hours (25th percentile) occurring when tidal currents were swiftest, the median depth of the 45 mesh leadline was only $0.3 \mathrm{~m}$ deeper than the 29 mesh net (Table 2). As current strength dropped, leadline depths slowly increased, but the difference in median depth across all nets was only $0.7 \mathrm{~m}$ at 12 tidal hours (50th percentile), and $1 \mathrm{~m}$ at 18 tidal hours (75th percentile). For half the tidal cycle, all net types remained in only the top $2.5 \mathrm{~m}$ of the water column. Only near slack water (last 4 tidal hours for 45 mesh nets and last 2 tidal hours for the 36 mesh net) did the depth of the leadlines drop to approach the potential maximum depths of 29,36 , and 45 mesh nets (3.7, 4.6 , and $5.7 \mathrm{~m}$ ). Nets of all mesh construction therefore responded similarly. As an empirical fish depth distribution suggests (Fig. 3, right column), it is only when tidal currents briefly stop running in Cook Inlet that the nets 


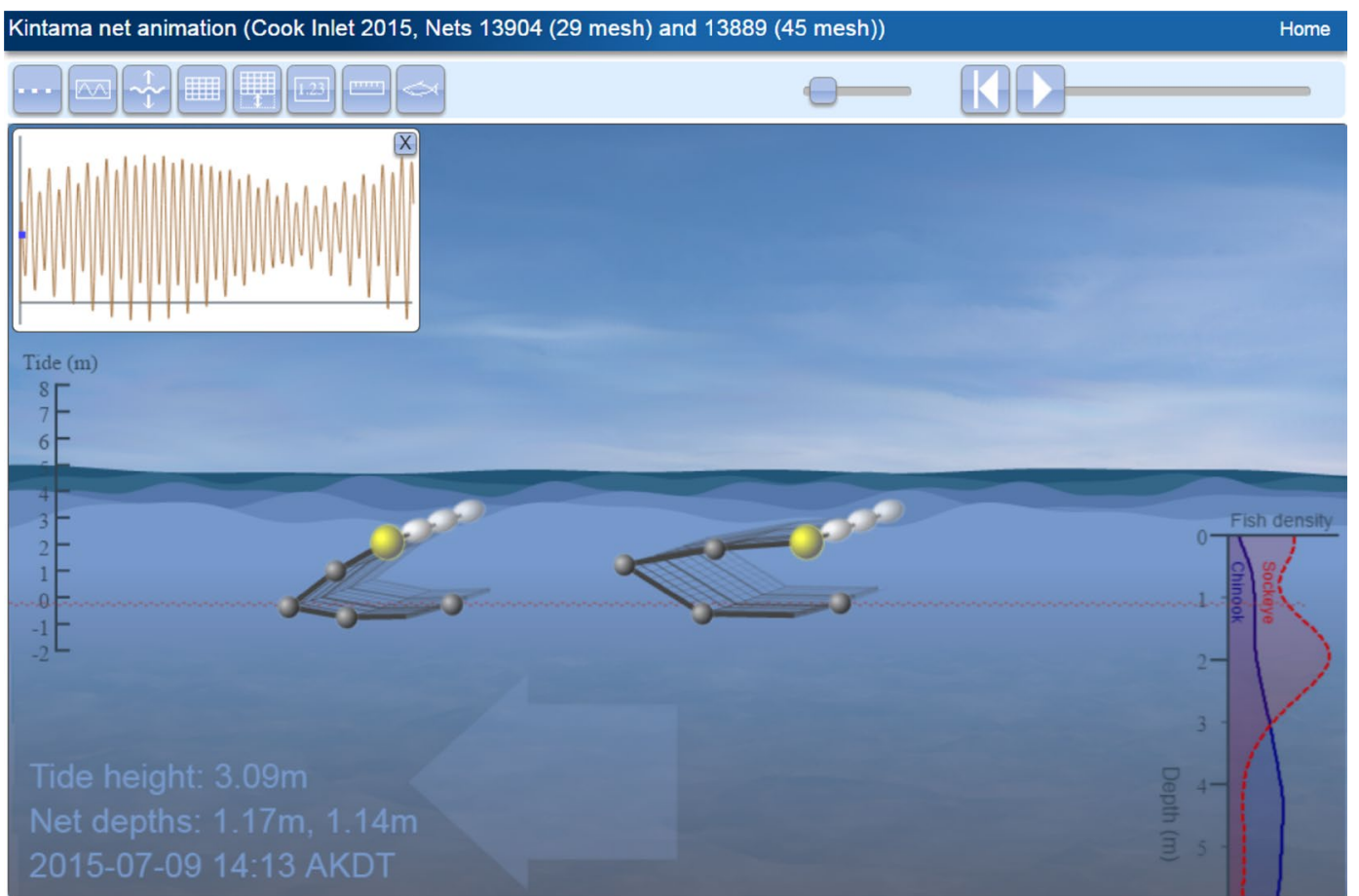

Fig. 2 Screen capture image of the side-by-side animation of the 29 and 45 mesh nets instrumented with multiple depth recorders (represented with gray balls). The large white arrow shows the direction the tidal current is running. The animator is available at http://kintama.com/animator/net/

dropped into the depths where Chinook salmon appear to migrate most commonly [16] and are exposed to capture.

\section{Discussion}

This study provides the first concrete data on how setnets actually fish in Cook Inlet, and the specific technical methods we report here likely have much broader potential application to managing bycatch worldwide (e.g., [23, 24]). The exceedingly shallow net depths we document in Cook Inlet were unexpected given the potential maximum depth of the nets. When tidal currents were strongest, the average leadline depth for all nets was $\sim 1.5 \mathrm{~m}$ (only $26 \%$ of the potential maximum fishing depth of a standard 45 mesh net), and leadlines sometimes reached as shallow as $0.6 \mathrm{~m}$ ( $11 \%$ of maximum depth), regardless of net construction. As current strength dropped, leadline depths gradually increased, but for half the tidal cycle all instrumented nets remained at less than half their maximum potential depth. Further, the leadlines of the 29 and 45 mesh nets differed by only $30 \mathrm{~cm}$ for the shallowest $25 \%$ of the total time that the nets were fished (and differed by only $\sim 70 \mathrm{~cm}$ and $\sim 1 \mathrm{~m}$ at the 50th and 75th percentiles). Although there was some variability in depth between individual nets (see Additional file 1; Fig. 3), and between the two areas chosen for the study (see Additional file 1), the depth differences were small relative to the large measured depth changes driven by the tides.

Data on leadline depth for the different nets can be combined with data on the depth distribution of Chinook and sockeye to assess potential changes in harvest. The fish depth distribution information was collected from a limited sample of 11 Chinook and 25 sockeye migrating near the boundary of the ESSN fishing zone (see [16] for details). Assuming the data also apply within the ESSN zone, then during times of strongest tidal flow the leadlines of all nets were lifted to slightly above the median migration depth of sockeye (about $1.8 \mathrm{~m}$ ), but entered into only the top $10 \%$ of the Chinook depth distribution. It was not until slack water when the nets extend down close to their potential maximum depths that the deeper nets dropped significantly into the depth distribution of Chinook, with the 45 mesh net approximately doubling Chinook exposure relative to the 29 mesh net (51 vs 19-26\% exposure over the $4 \mathrm{~h}$ of slack water). Because the sockeye depth distribution is more strongly surface oriented, switching from the 45 to the 29 mesh net should have a smaller effect on sockeye exposure at slack water, with 78 versus $66-71 \%$ of the sockeye depth distribution lying within the depth range of the two nets, respectively. 

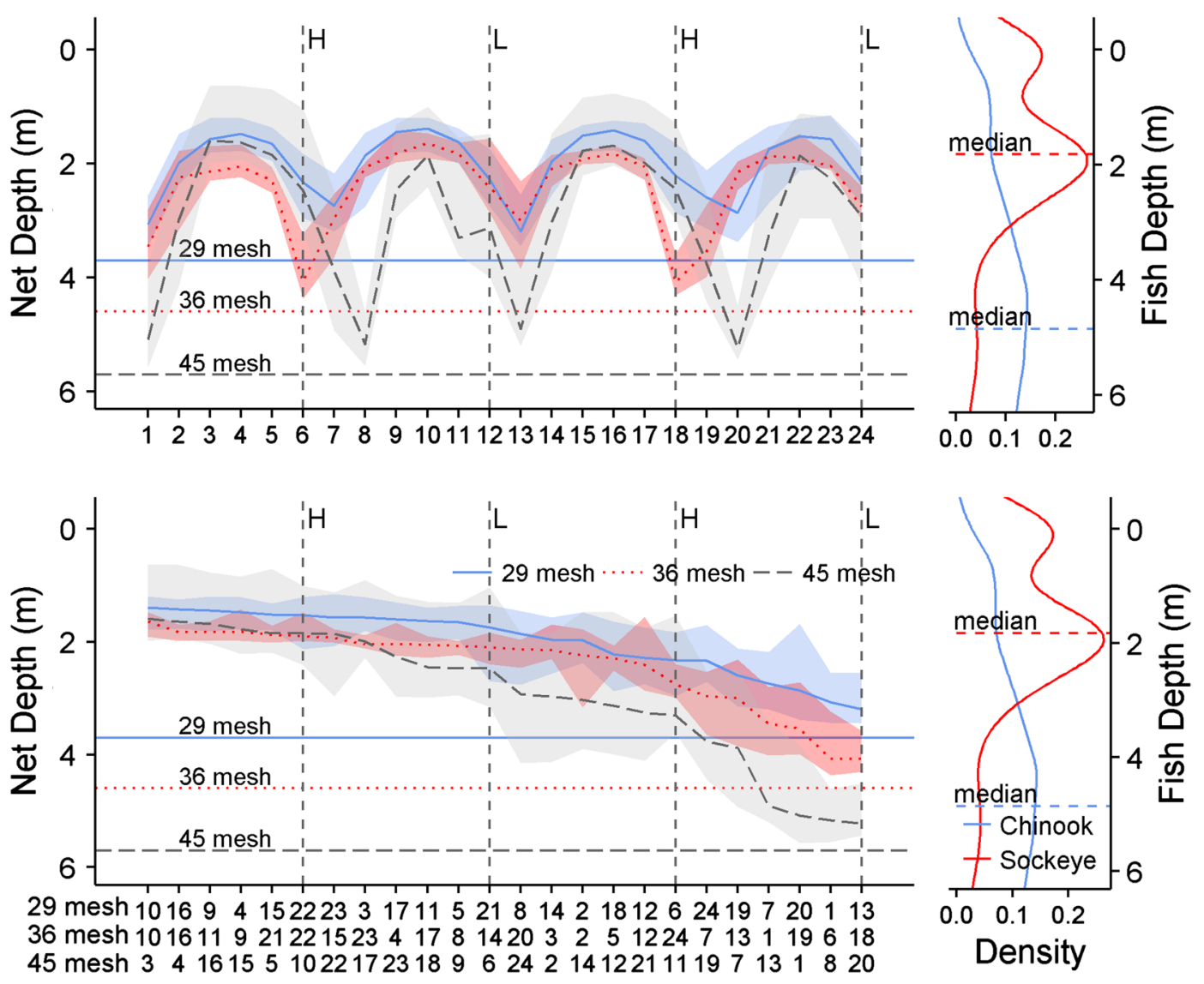

Tidal hour

Fig. 3 (Top) Leadline depth relative to the tidal cycle. Thick lines show the median of all depth measurements in each tidal hour; shaded regions show the 25th-75th depth percentiles. (Bottom) Leadline depths sorted from shallowest to deepest tidal hour, rather than chronologically. The stack of 3 numbers on the $x$-axis provides the tidal hour for each net type. Times of high $(H)$ and low $(L)$ tides are indicated, and the three horizontal lines show the potential maximum net depths assuming $5^{\prime \prime}$ mesh. For comparison, the right-hand plots in both panels show the depth distribution of Chinook and sockeye measured near the western boundary of the ESSN in 2013

Table 2 Median leadline depths (m), calculated using the depth data after ordering it from shallowest to deepest (medians are calculated after combining data for all similar net types)

\begin{tabular}{lllll}
\hline & \multicolumn{4}{l}{ Percentiles } \\
\cline { 2 - 5 } & 25th & 50th & 75th & 100th \\
\hline 29 mesh & 1.52 & 1.75 & 2.33 & 3.20 \\
36 mesh & 1.90 & 2.10 & 2.75 & 4.08 \\
45 mesh & 1.85 & 2.47 & 3.31 & 5.23 \\
Depth difference (29 and 45 mesh nets) & 0.33 & 0.72 & 0.98 & 2.03 \\
\hline
\end{tabular}

Although most Chinook are probably captured around slack water, it is unknown when during the tidal cycle most sockeye are harvested. With their surface-oriented depth distribution, sockeye are potentially exposed to the nets over much of the tidal cycle, but their direction and speed of migration within the ESSN relative to net orientation may change with the stage of the tide or time of day, and net efficiency is probably affected by the dramatic changes in net shape that must occur over the tidal cycle. Setnets (a form of gillnet) are usually thought to be most effective when they are hanging vertically, which occurs only at times of slack water in Cook Inlet. However, because both the leadline and floatline were secured to a series of anchors placed on the seafloor every $60 \mathrm{~m}$, setnets must become $\mathrm{C}$-shaped in cross section as current strength increases (Fig. 2), a shape which may also be quite effective at catching salmon in near-surface waters. Unfortunately, detailed information on catch rates at various stages of the tide is lacking.

One management practice that could potentially reduce Chinook harvest would be to institute fishing 
closures during the aggregate $\sim 4 \mathrm{~h}$ of slack water occurring each day when the nets reach their maximum depth. However, this is almost certainly infeasible-there are 4 tidal periods per day that all nets would need to be simultaneously lifted out of the water for relatively brief periods, and the time of slack water varies geographically as the tide progresses up Cook Inlet. Additionally, if most sockeye harvest occurs during slack water, then removing the nets during this period could have a large negative impact on the sockeye fishery.

A more practical alternative is to consider having the ESSN fishery switch to reduced-depth nets and avoid fishing in much of the Chinook depth distribution. At slack water when nets hang vertically and are thought to fish most effectively, switching to 29 mesh instead of 45 mesh nets would reduce Chinook exposure to capture by about half, but have a much smaller effect on sockeye exposure. The precise size of the reduction in sockeye harvest is somewhat difficult to predict because it depends not only on the depth data, but also on the unknown fishing efficiency of the nets over the full tidal cycle (i.e., at times beyond slack water). However, uncertainty in the predicted change in relative exposure of the two salmon species could be managed in practice by measuring subsequent escapement rates into the river and incorporating that information into existing management practice as part of an adaptive management experiment.

Our results depend on the assumption that the leadline depth measured at the sensors applies to the leadline depth of the entire net as well as to the broader population of nets, which seems reasonable. Close inspection of the individual leadline depth profiles (reported in the Additional files) shows no indication that the leadlines were contacting the bottom. Further research on the depth distribution of sockeye and Chinook within the ESSN, as well as on net efficiency at various stages of the tide, could usefully strengthen our results and their potential utility to management.

\section{Conclusions}

In the near-term, reducing the maximum depth of all nets in the fishery to 29 meshes (or less) would likely bring a potentially significant reduction in Chinook harvest. Sockeye harvest rates would be affected, but losses could be mitigated by small increases in the amount of allowable fishing time while still reducing overall Chinook harvests. However, we suspect that large increases in both the overall economic value of the Cook Inlet salmon fishery and escapement to various regions within Cook Inlet could be simultaneously attained by applying formal optimization approaches to combine the data on fish depths and net dynamics with information on the biological productivity and current status of all Cook Inlet salmon stocks. The dynamics are relatively complicated and beyond our current goals; however, such a strategy could potentially enable managers to achieve high rates of population rebuilding while maintaining acceptable levels of employment and revenue (harvest) in the near-term.

Such an analysis would ideally involve further telemetry work to verify the depth distribution of the two species directly within the ESSN fishing zone, as well as measurements to determine how the effectiveness of the nets changes with the tide. However, in our view further resolving the potential limitations in the telemetry data is likely less important than assessing a range of management strategies that could take advantage of the differences in migration depth, as these depth differences are already widely recognized by fishermen in at least a qualitative way. Such an approach could potentially lead to substantial economic and social gains [25-28]. More importantly, a broader assessment of management strategies would allow laying out the potential gains and losses to all stakeholders, as the sociological issues surrounding trust and acceptance $[8-10,15,17,29,30]$ are at least as challenging as the scientific ones. Open sharing of telemetry data and quantifying in a transparent way the economic and conservation benefits various management strategies might achieve could contribute significantly to building consensus between user groups.

\section{Additional files}

Additional file 1. Supplementary boxplots of net depth measurements.

Additional file 2. Figures showing the complete time series of net depth measurements for depth recorders attached to net leadlines.

Additional file 3. Figures showing the complete time series of net depth measurements for the multi-instrumented nets fished at Site A.

Additional file 4. Summary tables of net depth measurements

\section{Authors' contributions}

DW involved in all aspects. AP analyzed the data and prepared the manuscript. PW involved in equipment preparation and data download. All authors read and approved the final manuscript.

\section{Acknowledgements}

Our study would not have been possible without the support of several ESSN commercial fishermen: Gary Hollier, Ken Coleman, Brent Johnson, and Richard Person. We thank each of them for their willingness to explore the possibilities concerning how their nets actually fish, and placing their trust in us to represent the results in a frank and open-minded manner. Gary Hollier deserves particular credit for his leadership in the complex (and frequently fraught) world of Cook Inlet fish politics.

\section{Competing interests}

DWW is President and owner of Kintama Research Services Ltd., an environmental consultancy focused on the development of innovative applications of telemetry to improve fisheries management. ADP and PW are employed at Kintama. All authors received a financial benefit in the course of conducting 
this study and their future salaries depend on their continued technical and scientific performance, which includes the publication of this study.

\section{Availability of data and materials}

Available from the authors without restriction.

\section{Funding}

This study was initially internally funded by Kintama in order to proactively collect data believed to be important for addressing the issues outlined in this report. Subsequent to instrument recovery, funding was obtained to cover staff time for writing a report outlining the findings and addressing the identified management concerns. The funder (the Matanuska-Susitna Borough, 350 East Dahlia Avenue, Palmer, Alaska, USA 99645) played no role in the design of the study nor the conclusions reached.

\section{Publisher's Note}

Springer Nature remains neutral with regard to jurisdictional claims in published maps and institutional affiliations.

Received: 15 September 2016 Accepted: 27 April 2017 Published online: 08 May 2017

\section{References}

1. Lewis B, Grant WS, Brenner RE, Hamazaki T. Changes in size and age of Chinook Salmon Oncorhynchus tshawytscha Returning to Alaska. PLoS ONE. 2015;10:e0130184. doi:10.1371/journal.pone.0130184.

2. Orsi J. The Alaska Chinook Salmon Production Enigma... What's going on? ONCORHYNCHUS XXXIII. 2013;1-5. http://www.afs-alaska.org/wpcontent/uploads/Onco332.pdf.

3. Harrison HL, Loring PA. Larger than life: the emergent nature of conflict in Alaska's Upper Cook Inlet salmon fisheries. SAGE Open. 2014. doi:10.1177/2158244014555112.

4. Sechrist K, Rutz J. The history of upper Cook Inlet salmon fisheriesa century of salmon. Juneau, AK: Alaska Dept of Fish and Game; 2014:8. http://www.adfg.alaska.gov/index.cfm?adfg=wildlifenews. view_article\&articles_id=639.

5. Seung CK, Muse B, Waters EC. Net economic impacts of recent Alaska Salmon Fishery Failures and Federal Relief. North Am J Fish Manag. 2016;36:351-62. doi:10.1080/02755947.2015.1120831.

6. Loring PA. The political ecology of gear bans in two fisheries: Florida's net ban and Alaska's Salmon wars. Fish Fish. 2016. doi:10.1111/faf.12169.

7. Krupa MB. Who's who in the Kenai River Fishery SES: a streamlined method for stakeholder identification and investment analysis. Mar Policy. 2016;71:194-200. doi:10.1016/j.marpol.2016.06.001.

8. Loring PA, Harrison HL, Gerlach SC. Local perceptions of the sustainability of Alaska's highly contested Cook Inlet salmon fisheries. Soc Nat Resour. 2014;27:1-15. doi:10.1080/08941920.2013.819955.

9. Loring PA, Harrison HL. "That's what opening day is for": social and cultural dimensions of (not) fishing for salmon in Cook Inlet, Alaska. Marit Stud. 2013;12:1-19. doi:10.1186/2212-9790-12-12.

10. Medred C. The dying Kenai kings. 2016. https://craigmedred. news/2016/05/05/the-dying-kenai-kings/.

11. Welch L. Looking for answers to Alaska's chinook decline. Anchorage, Alaska: Alaska Daily News; 2014. http://www.adn.com/print/ article/20140825/laine-welch-looking-answers-alaskas-chinook-decline.

12. Morris WS. Conserving the Kenai king is a mandate for board, ADFG. Alaska J Commerce 2014. http://www.alaskajournal. com/Alaska-Journal-of-Commerce/January-Issue-2-2014/ Conserving-the-Kenai-king-is-a-mandate-for-board-ADFG/.

13. Medred C. In a grand experiment, Kenai setnetters try using shallower nets to protect king salmon. Anchorage, AK; 2014. http://www.adn. com/article/20140717/grand-experiment-kenai-setnetters-try-usingshallower-nets-protect-king-salmon.

14. McChesney R. Board adopts further restrictions to Cook Inlet setnet fishery. Alaska J Commerce 2014;2:4. http://www.alaskajournal.com/Alaska-Journal-of-Commerce/February-Issue-2-2014/ Board-adopts-further-restrictions-to-Cook-Inlet-setnet-fishery/.
15. Alaska Supreme Court: COOK INLET FISHERMAN'S FUND, Appellant, v. STATE of Alaska, DEPARTMENT OF FISH \& GAME, Appellee. In Book COOK INLET FISHERMAN'S FUND, Appellant, v. STATE of Alaska, DEPARTMENT OF FISH \& GAME, Appellee.; 2015. http://caselaw.findlaw.com/ak-supremecourt/1714157.html\#sthash.MFPtOYtb.dpuf.

16. Welch D, Porter A, Winchell P. Migration behavior of maturing sockeye (Oncorhynchus nerka) and Chinook salmon (O. tshawytscha) in Cook Inlet, Alaska, and implications for management. Anim Biotelemetry. 2014;2:35. doi:10.1186/s40317-014-0018-3.

17. Willette TM, Shields P, Volk EC. Oversimplification of complex harvest modeling issues outlined in Welch et al. (2014). Anim Biotelemetry. 2014;2015(3):4. doi:10.1186/s40317-015-0027-x.

18. Welch DW, Porter AD, Winchell P. Response to Willette et al. (2015). Anim Biotelemetry. 2015;2015(3):1-2. doi:10.1186/s40317-015-0042-y.

19. ADFG. 2014-2017 Cook Inlet area commercial salmon fishing regulations. Alaska Dept of Fish and Game; 2014:115. http://www.adfg.alaska.gov/ static/regulations/fishregulations/pdfs/commercial/2014_2017_Cook_ Inlet_Finfish.pdf.

20. Robinson PW, Villegas-Amtmann S, Costa DP. Field validation of an inexpensive time-depth recorder. Mar Mamm Sci. 2009;25:199-205. doi:10.1111/j.1748-7692.2008.00227.x.

21. Project Signal: Signal Processing. http://r-forge.r-project.org/projects/ signal/.

22. R Core Team. R: a language and environment for statistical computing. R Foundation for Statistical Computing, Vienna, Austria 2015. https:// www.R-project.org/.

23. Northridge S, Coram A, Kingston A, Crawford R. Disentangling the causes of protected-species bycatch in gillnet fisheries. Conserv Biol. 2016. doi:10.1111/cobi.12741.

24. Bergstedt RA, Argyle RL, Taylor WW, Krueger CC. Seasonal and diel bathythermal distributions of Lake Whitefish in Lake Huron: potential implications for Lake Trout bycatch in commercial fisheries. North Am J Fish Manag. 2016;36:705-19. doi:10.1080/02755947.2016.1165771.

25. Williams BK. Review of dynamic optimization methods in renewable natural resource management. Nat Resour Model. 1989;3:137-216.

26. Turvey R. Optimization and suboptimization in fishery regulation. Am Econ Rev. 1964;54:64-76. http://www.jstor.org/stable/1810898.

27. Mendelssohn R, Sobel MJ. Capital accumulation and the optimization of renewable resource models. J Econ Theory. 1980;23:243-60. doi:10.1016/0022-0531(80)90009-5.

28. Hof J, Kent B, Baltic T. An iterative multilevel approach to natural resource optimization: a test case. Nat Resour Model. 1992;6(1):1-22.

29. Loring PA. Alternative perspectives on the sustainability of Alaska's commercial fisheries. Conserv Biol. 2013;27:55-63. doi:10.1111/j.1523-1739.2012.01938.x.

30. Fazzino DV, Loring PA. From crisis to cumulative effects: food security challenges in Alaska. NAPA Bull. 2009;32:152-77. doi:10.1111/j.1556-4797.2009.01033.x.

\section{Submit your next manuscript to BioMed Central and we will help you at every step:}

- We accept pre-submission inquiries

- Our selector tool helps you to find the most relevant journal

- We provide round the clock customer support

- Convenient online submission

- Thorough peer review

- Inclusion in PubMed and all major indexing services

- Maximum visibility for your research

Submit your manuscript at www.biomedcentral.com/submit
BioMed Central 